\title{
Development and Evaluation of a New Serious Game for Continuing Medical Education of General Practitioners (Hygie): Double-Blinded Randomized Controlled Trial
}

Louis-Baptiste Jaunay ${ }^{1,2}$, MSc, MD; Philippe Zerr², MD; Lino Peguin ${ }^{2}$; Léandre Renouard ${ }^{2}$; Anne-Sophie Ivanoff ${ }^{2}$, MD; Hervé Picard ${ }^{3,4}$, MD; James Griffith ${ }^{5}$ PhD; Olivier Chassany ${ }^{6,7}, \mathrm{MD}, \mathrm{PhD}$; Martin Duracinsky ${ }^{6,7,8}, \mathrm{MD}, \mathrm{PhD}$

\footnotetext{
${ }^{1}$ Département de Médecine Générale, Sorbonne Paris Cité, Université Paris-Descartes, Paris, France

${ }^{2}$ Département de Médecine Générale, Sorbonne Paris Cité, Université Paris-Diderot, Paris, France

${ }^{3}$ Service de Recherche Clinique, Fondation Rothschild, Paris, France

${ }^{4}$ Pole Recherche et Evaluation Scientifique, Cabinet Ipso, Paris, France

${ }^{5}$ Department of Medical Social Sciences, Feinberg School of Medicine, Northwestern University, Chicago, IL, United States

${ }^{6}$ Patient-Reported Outcomes Research, Sorbonne Paris Cité, Université Paris-Diderot, Paris, France

${ }^{7}$ Unité de Recherche Clinique en Economie de la Santé, Hôpital Hôtel-Dieu, Assistance Publique Hôpital de Paris, Paris, France

${ }^{8}$ Médecine Interne et Immunologie Clinique, Hôpital Bicêtre, Assistance Publique Hôpital de Paris, Paris, France
}

\section{Corresponding Author:}

Louis-Baptiste Jaunay, MSc, MD

Département de Médecine Générale

Sorbonne Paris Cité

Université Paris-Descartes

24 Rue du Faubourg Saint-Jacques

Paris, 75014

France

Phone: 33144412363

Fax: 33144412364

Email: drjaunay@gmail.com

\section{Abstract}

Background: Continuing medical education is important but time-consuming for general practitioners (GPs). Current learning approaches are limited and lack the ability to engage some practitioners. Serious games are new learning approaches that use video games as engaging teaching material. They have significant advantages in terms of efficiency and dissemination.

Objective: The aim of this study was to create a serious game and to evaluate it in terms of effectiveness and satisfaction, comparing it with a traditional method of continuing education-article reading.

Methods: We produced a prototype video game called Hygie on the 5 most common reasons of consultation in general practice using 9 articles from independent evidence-based medicine journals (reviews from Prescrire and Minerva). We created 51 clinical cases. We then conducted a double-blinded randomized trial comparing the learning provided by a week of access to the game versus source articles. Participants were GPs involved as resident supervisors in 14 French university departments of family practice, recruited by email. Primary outcomes were (1) mean final knowledge score completed 3 to 5 weeks after the end of the intervention and (2) mean difference between knowledge pretest (before intervention) and posttest ( 3 to 5 weeks after intervention) scores, both scaled on 10 points. Secondary outcomes were transfer of knowledge learned to practice, satisfaction, and time spent playing.

Results: A total of 269 GPs agreed to participate in the study. Characteristics of participants were similar between learning groups. There was no difference between groups on the mean score of the final knowledge test, with scores of 4.9 (95\% CI 4.6-5.2) in the Hygie group and 4.6 (95\% CI 4.2-4.9) in the reading group $(P=.21)$. There was a mean difference score between knowledge pre- and posttests, with significantly superior performance for Hygie (mean gain of 1.6 in the Hygie group and 0.9 in the reading group; $P=.02$ ), demonstrating a more efficient and persistent learning with Hygie. The rate of participants that reported to have used the knowledge they learned through the teaching material was significantly superior in the Hygie group: 77\% (47/61) in the Hygie group and 53\% (25/47) in the reading group; odds ratio 2.9, 95\% CI 1.2-7.4. Moreover, $87 \%$ of the opinions were favorable, 
indicating that Hygie is of interest for updating medical knowledge. Qualitative data showed that learners enjoyed Hygie especially for its playful, interactive, and stimulating aspects.

Conclusions: We conclude that Hygie can diversify the offering for continuing education for GPs in an effective, pleasant, and evidence-based way.

Trial Registration: ClinicalTrials.gov NCT03486275; https://clinicaltrials.gov/ct2/show/NCT03486275

(J Med Internet Res 2019;21(11):e12669) doi: $\underline{10.2196 / 12669}$

\section{KEYWORDS}

general practice; continuing medical education; evidence-based medicine; video games; randomized controlled trial; pedagogy

\section{Introduction}

\section{Background}

General practitioners (GPs) update their medical knowledge throughout their professional life to maintain knowledge acquired during their initial studies and to be abreast of the latest scientific advances.

Continuing medical education, however, can be tedious and sporadic because a considerable amount of new medical data and new literature are being continuously released, varying in quality and accessibility. The busy practitioner has limited time to consult this information [1-3], and traditional teaching methods such as lectures and group discussion have small and short-lasting effects [4]. As a result, clinical care may not be in line with the latest science, leading to poorer health outcomes [5]. Thus, new, efficient, and stimulating teaching methods are required.

New teaching materials called serious games are efficient [6,7] and easily disseminated methods for education [8]. Indeed, they offer the possibility of combining learning activities such as testing [9], feedback [10], spaced repetition [11], and problem-based learning $[12,13]$ with a positive experience. Learning challenges can be provided by these games $[14,15]$ in a risk-free environment [16]. Therefore, serious games give active participation and autonomy to the learner, both of which are crucial qualities in adult education [17].

Few serious games have been developed with the goal of facilitating continuous medical education for health professionals [18] and GPs [19,20]. To our knowledge, no existing game covers several topics related to family medicine.

\section{Objectives}

The aim of this study was to develop a prototype of a new serious game called Hygie for continuing medical education for the GP and to assess its effectiveness and user acceptance as compared with a traditional activity (article reading) in a randomized trial.

\section{Methods}

\section{Design and Development of Hygie}

We produced a prototype video game called Hygie in which the player is a GP in the process of treating several patients. We defined topics for this prototype based on the 5 most frequent reasons for consultation in France [21]: hypertension, health check and prevention, dyslipidemia, acute fever, and rhinopharyngitis.

For these 5 topics, we reviewed 9 articles in 2 French evidence-based journals: 6 from Prescrire and 3 from Minerva [22-30]. We selected these 2 journals because they provide robust evidence-based recommendations and are strictly independent from industrial and institutional influences.

From these 9 articles, we created 51 short clinical cases, each having 1 question that could be answered either by multiple choice or free text.

The game was coded using HTML 5, Cascading Style Sheets 3, JavaScript (ECMAScript 2015), and Hypertext Preprocessor (PHP) 7. Graphics were created using Adobe Illustrator and Adobe Photoshop (Figure 1).

Learning methods incorporated into the game included statement of educational objectives, immersion in a general medical consultation setting, problem-based learning with active restitution of knowledge, spaced recall, stimulation of intrinsic motivation by earning points, and having goals and levels with a "final boss" for each level. Humoristic elements such as puns in patients' names were included to maximize engagement.

A preliminary test phase was conducted with 11 GPs and 9 residents in general practice. The preliminary test allowed us to detect and solve bugs, clarify questions, and sort questions into 5 levels of difficulty.

The prototype of the game is freely accessible on the Web [31]. 
Figure 1. Start of a clinical case in Hygie.

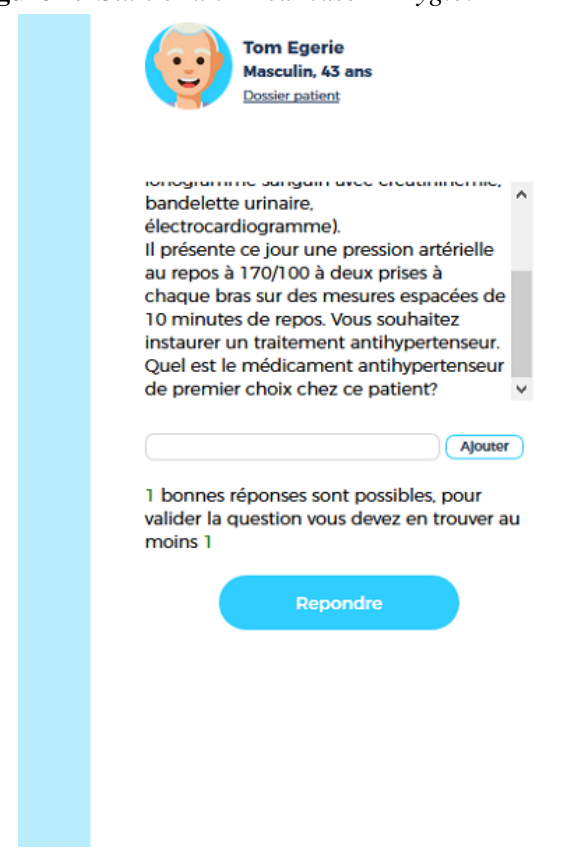

\section{Study Design}

We performed a double-blind randomized controlled trial to assess the effectiveness of Hygie as a method for continuing education for GPs as compared with a traditional article reading activity with the same content.

We asked all 35 French university departments of family practice to contact GPs involved as resident supervisors by email to participate in a real-life experience learning where they would have access to an electronic learning (e-learning) teaching material for 7 days, without mentioning the nature of the teaching materials. Institutional affiliations of the investigators were indicated at the end of the email.

Information was delivered to participants about the purpose, the duration, the time to devote to the study, and anonymization of results.

After agreeing to participate, GPs accessed the study website where they completed a demographic questionnaire, a knowledge pretest of 5 questions on each of the 5 reasons for consultation. They were randomized using the rand function of PHP language (allocation ratio 1:1) to either the intervention group (Web access to Hygie for 1 week) or to the control group (access online to the 9 articles). Participants had an individual login, allowing them to access only the teaching material assigned to them. They did not know if they were assigned to the intervention or control group and did not know which intervention was performed in the other group. Data were collected on a Structured Query Language database.

After 1 week of free access to their respective teaching material (serious game Hygie vs articles), access was terminated. Reminders were sent to the 2 groups within 3 and 6 days of access to teaching material.

After 3 weeks without access to the teaching materials, participants received a final, 20-item knowledge questionnaire (Figure 2). Among the 20 questions, 5 were common with pretest. Only those participants who had completed the final questionnaire were analyzed.

Figure 2. Study design.

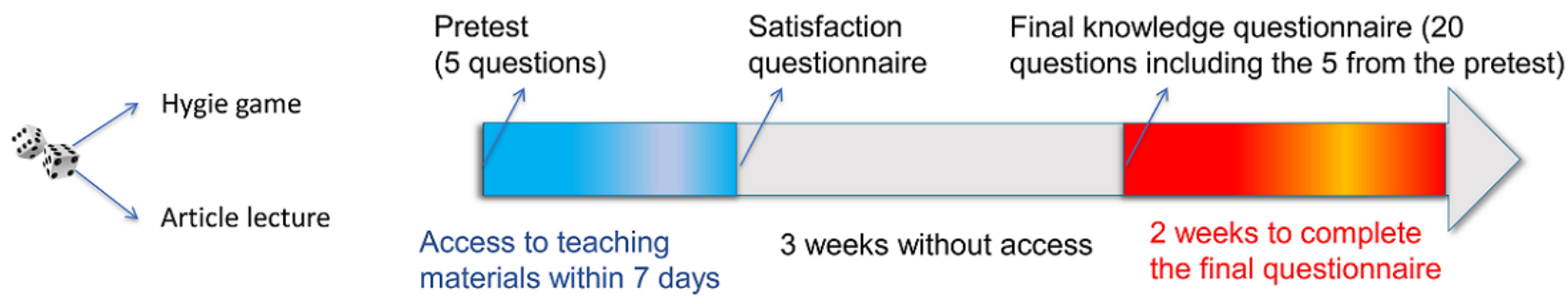

Primary outcomes were (1) dynamic and (2) static knowledge assessed by questionnaires:

1. A Dynamic Questionnaire-5 (DQ-5) with 5 items compared individual change of score between pretest (before intervention) and posttest (3-5 weeks after intervention). It was a 5-item questionnaire with each of the 5 questions weighted by a scale ranging from 1 to 3 according to its importance for practice and a global score from 0 to 14 . 
The goal of this questionnaire was to assess progression of each participants. For a simpler interpretation, we scaled the DQ-5 score to be out of 10 rather than 14 .

2. A Static Questionnaire-20 (SQ-20) measured mean final score 3 to 5 weeks after intervention. It was a 20-item questionnaire ( 5 of the dynamic questionnaire plus 15 other questions), with each of the 20 questions weighted by a scale ranging from 1 to 3 according to its importance for practice and a global score from 0 to 58. The goal of this questionnaire was to compare groups, minimizing the potential carryover effects induced by the pretest questionnaire. Like for the DQ-5, for interpretation, we rescaled the SQ-20 to a 0 to 10 scale (rather than 0-58).

Here is an example of a knowledge question that appears in both dynamic and static questionnaires and the scoring method:

Question: Which cholesterol-lowering drugs have shown a decrease in mortality and morbidity?

Expected answers (free text): pravastatin, simvastatin. Scoring method: It was rated 3 points out of 14;

If the 2 right molecules (pravastatin and simvastatin) are mentioned: 3 points

If 1 good molecule among pravastatin and simvastatin is mentioned: 1 point

In all other cases: 0 points.

The 2 knowledge questionnaires and their scale were written from the source articles by 3 experienced physicians who had no information about the game content, with instructions to identify practice-relevant issues in the articles. Participants' questionnaires were scored blindly by a physician not involved in the other stages of the study.

Secondary outcomes were (1) the use in medical practice of the knowledge acquired through the teaching material assessed at the time of the final questionnaire (participants answered the question "In the course of your practice, did you use the knowledge you learned through the teaching material?"), (2) time spent playing by participants assigned to Hygie, and (3) a satisfaction questionnaire. The satisfaction questionnaire, composed of 8 questions and completed at the end of the 1-week learning period, included quantitative and qualitative data about participant satisfaction, time reported as spent on the materials, and additional demographic data (eg, workplace and usual training materials for continuing education). Qualitative data were analyzed by content for themes related to effective learning as well as to illuminate potential strengths and weaknesses of Hygie. The average total time spent on the Hygie game was measured via server usage data. Average total time spent on the articles was not collected because participants could download the articles and read it offline.

\section{Statistical Analysis}

The answers to the knowledge and satisfaction questionnaires were collected on the framaform website. Statistical analyses were performed using $\mathrm{R}$ software (R Foundation for Statistical Computing) [32]. The 2 groups were compared using Fisher exact tests for nominal variables and Welch $t$ tests for quantitative variables. Differences with $P<.05$ were considered significant.

\section{Sample Size}

The number of participants required with $80 \%$ power (1-beta) and $5 \%$ type I error was estimated before the study. A total of 128 participants were needed to detect a difference of 2 points out of 10 between the groups on the final questionnaire, assuming that the participants in the Hygie group had a final score of 8 out of 10 on average.

\section{Ethics}

Participation was anonymous and voluntary. Participants began the study by clicking a link to teaching materials.

The study was approved by the Committee for the Evaluation of the Ethics of Research Projects of hospital Robert Debré $\mathrm{n}^{\circ}$ $2017 / 359$.

\section{Results}

\section{Participant Statistics}

A total of 14 university departments from 8 French regions accepted to participate in this study. A total of 3398 GPs were invited to participate in this study by email. Of these, 269 participants $(7.9 \%$ ) accepted to participate in the study. Recruitment occurred between May 31, 2017, and June 27, 2017. A total of 108 participants completed the study and were analyzed. There was no difference of baseline characteristics between participants who completed and participants who did not complete the study.

The inclusion flow diagram according to Consolidated Standards of Reporting Trials recommendations [33] is shown in Figure 3.

Baseline characteristics of participants in both groups were comparable (Table 1). Mean age was 40.9 years, there was a majority of women, and an urban setting was the most common. The most widely used continuing education method was reading print journals.

The DQ-5 pretest mean score was identical in the 2 groups: 3.4 (95\% CI 2.9-3.8) in the intervention group and 3.8 (95\% CI $3.2-4.3)$ in the control group $(P=.27$, not significant).

Average time between stopping access to support and completing the final questionnaire was similar in the 2 groups: 25.3 days (95\% CI 24.2-26.5) in the Hygie group and 27.5 days (95\% CI 26.3-28.7) in the control group. 
Figure 3. Flow diagram.

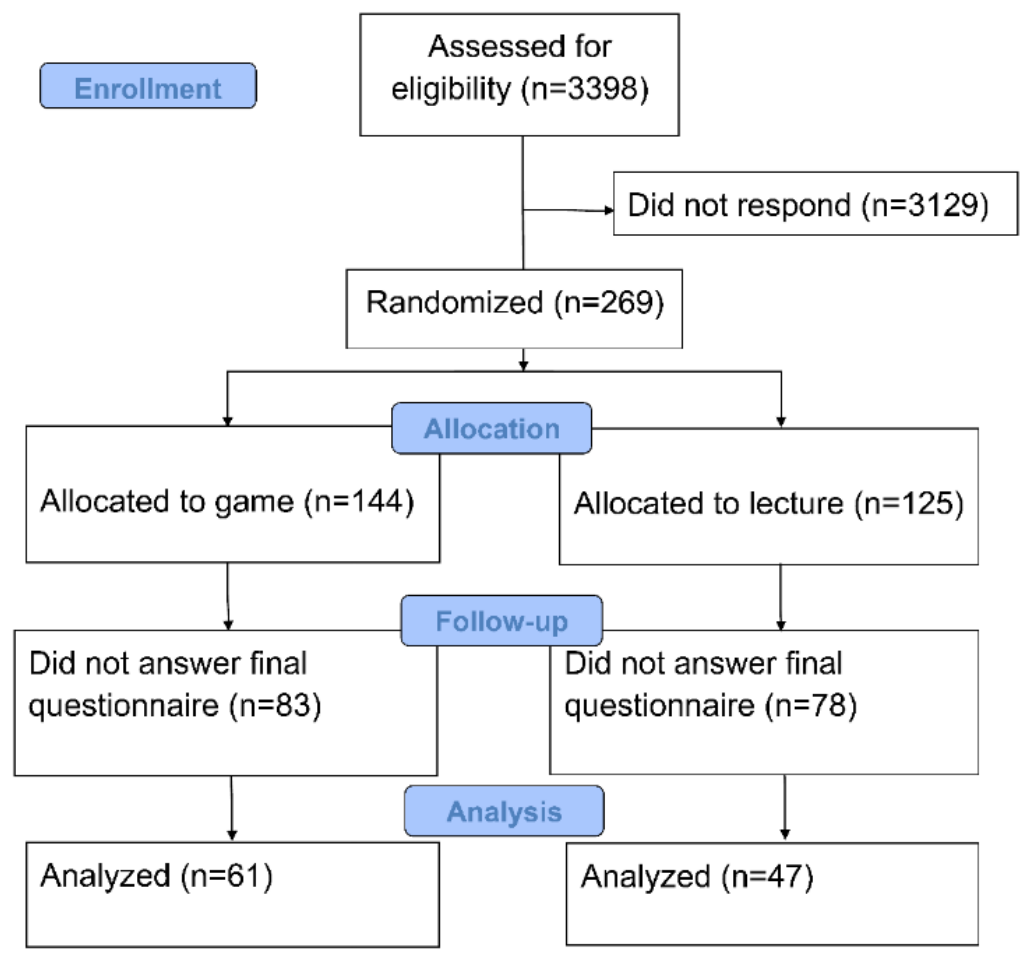

Table 1. Characteristics of analyzed participants allocated to each intervention (Hygie or control) at baseline ( $\mathrm{n}=108)$.

\begin{tabular}{|c|c|c|}
\hline Characteristics of participants & Hygie group $(\mathrm{n}=61)$ & Reading group $(n=47)$ \\
\hline \multicolumn{3}{|l|}{ Gender, n (\%) } \\
\hline Female & $30(49)$ & $27(57)$ \\
\hline Male & $31(51)$ & $20(43)$ \\
\hline Mean age (min-max) & $39.8(27-67)$ & $42.4(28-64)$ \\
\hline Dynamic Questionnaire-5 pretest, mean score $(95 \% \mathrm{CI})$ & $3.4(2.9-3.8)$ & $3.8(3.2-4.3)$ \\
\hline \multicolumn{3}{|l|}{ Workplace setting, n (\%) } \\
\hline Rural & $31(51)$ & $35(74)$ \\
\hline Semirural & $23(38)$ & $7(15)$ \\
\hline Urban & $7(11)$ & $6(13)$ \\
\hline \multicolumn{3}{|l|}{ Continuous teaching material, $\mathrm{n}(\%)$} \\
\hline Paper journals & $51(84)$ & $39(83)$ \\
\hline Internet journals & $23(38)$ & $23(49)$ \\
\hline Internet sites & $36(59)$ & $33(70)$ \\
\hline Onsite courses & $48(79)$ & $33(70)$ \\
\hline Peer group training & $35(57)$ & $20(43)$ \\
\hline Medical visitors & 5 & 12 \\
\hline
\end{tabular}

\section{Outcomes}

\section{Knowledge}

The final SQ-20 mean score was similar in the 2 groups: Hygie group 4.9 (95\% CI 4.6-5.2) and control group 4.6 (95\% CI 4.2-4.9; $P=.21$, not significant).
The final DQ-5 mean score (5-item posttest) was also similar in the 2 groups: Hygie group 5.0 (95\% CI 4.6-5.4) and control group 4.7 (95\% CI 4.2-5.1; $P=.26$, not significant).

The mean individual change of DQ-5 score between pre- and posttest was significantly superior to 0 in the Hygie group with a mean gain of $1.6(95 \%$ CI $1.2-2.1 ; P<.001)$ and in control group with a mean gain of 0.9 (95\% CI $0.5-1.4 ; P<.001)$. 
For the critical test of our trial, this mean individual change of DQ-5 score between pre- and posttest at 3 to 5 weeks was significantly superior in the Hygie group compared with the reading group, with a difference of $0.7(95 \% \mathrm{CI} 0.1-1.3 ; P=.02$; Figure 4).

Figure 4. Individual change of score in both groups, shown as density and number of participants. DQ-5: Dynamic Questionnaire-5.
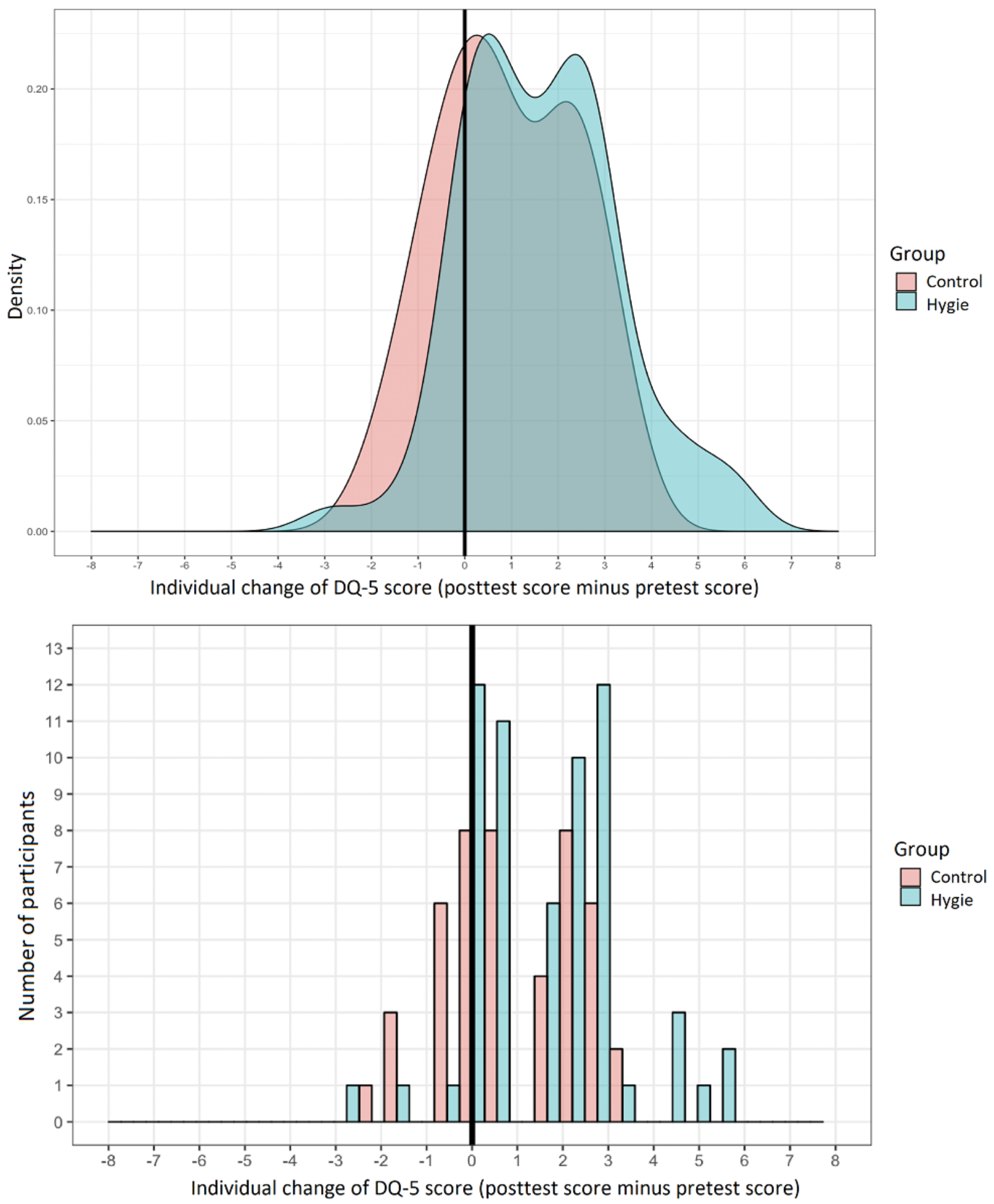

\section{Transfer to practice}

For the question "In the course of your practice, did you use the knowledge that you learned through the teaching material?," the percentage of participants reporting "yes" was significantly greater in the Hygie group (77\% in the Hygie group vs 53\% in the reading group; odds ratio $2.9,95 \%$ CI 1.2-7.4; Table 2). 
Table 2. General practitioners' responses to "In the course of your practice, did you use the knowledge you learned through the teaching material?"

\begin{tabular}{lll}
\hline Response & Hygie group, $\mathrm{n}(\%)$ & Reading group, $\mathrm{n}(\%)$ \\
\hline Yes & $47(77)$ & $25(53)$ \\
No & $14(23)$ & $22(47)$ \\
\hline
\end{tabular}

Players could rate clinical cases in terms of "usefulness to practice" just after resolving the cases. A total of 1464 clinical case scores were given, and the average score given was 4.14 out of 5 .

\section{Satisfaction and Qualitative Data}

In the satisfaction survey, $87 \%$ of Hygie group participants answered "yes" to the question "Do you think that Hygie is of interest for updating your medical knowledge?" and $75 \%$ answered "yes" to the question "Do you think that Hygie should be allowed for continuing education credits?".

The qualitative reasons spontaneously mentioned by the participants also justified Hygie, including the following themes:

- Effective learning: the characteristics of the game (subthemes mentioned the following: speed, simple learning, and effective information assimilation), informative content (key messages, relevance of themes, clarity, and referenced responses), and its mechanisms (repetition of clinical cases promoting memorization, cognitive conflict that allows for better memorization, and allows one to learn test with real-life scenarios).

- An enjoyable experience (subthemes mentioned the following: playful and fun) with stimulating challenges (challenging stimulation and real-time style mimics the clinic): $36 \%$ of participants of the Hygie group answered "yes" to the question "Did this session make you want to consult medical journals more regularly or take out a subscription?," which suggests that gaming encourages players to read journals, considering that $73 \%$ of GPs already reported consulting Prescrire regularly and 12\% reported consulting Minerva.

\section{Time Spent on Supports}

The average total time spent on the Hygie game, measured via server usage data for the included participants, was $43 \mathrm{~min}$. The average time per game session was $10 \mathrm{~min}$ and 50 seconds. Participants self-reported the time they spent on learning materials in the satisfaction questionnaire through a discontinuous quantitative variable. The most common responses were " 45 to 60 minutes" in the Hygie group and "10 to 20 minutes" in the reading group.

\section{Success Rate and Comments on Game Questions}

The overall success rate for clinical cases was $67 \%$. Participants' comments on clinical cases reflected the cognitive conflict produced in players by the system of interaction between the GPs knowledge and the "model" proposed by the game: some agreed with the answer (eg, "bravo"), whereas others criticized the clarity of the question (eg, "one could specify [...]") or criticized the answer based on their practice (eg, "I would have liked to do [...] before treating") or other sources (eg, "recommendations on this topic include [...]").

\section{Discussion}

\section{Principal Findings}

To our knowledge, Hygie is the first continuing education material of this type; it is the first educational video game developed for and by GPs. Hygie was created without external funding and independently of the pharmaceutical and medical device industries. Moreover, it is based on reliable sources that are helpful to GPs in maintaining and expending their knowledge. Finally, it is unique because of its extensive evaluation among a significant number of GPs from several regions of France. The use of both a double-blinded randomized trial and a satisfaction questionnaire evaluation differentiates Hygie from other serious health games in existence, with a few exceptions such as InsuOnline [20]. Our study shows that it is feasible to create an engaging educational video game, including validation in a randomized trial, without influence of public or private financing.

Our results have shown that giving access to the Hygie game to GPs in "real life" conditions (ie, where learner decided when, where, and how much time he or she wants to spend learning) results in a persistent learning at 3 to 5 weeks. Furthermore, giving access to Hygie resulted in a better improvement in medical knowledge compared with giving access to articles, which is the traditional method. In addition, this knowledge seems to be more easily transferable to medical practice, as shown by the greater proportion of GPs reporting having used the knowledge in their own practices as compared with traditional journal article reading. This result suggests that serious games may engender better transfer of knowledge to real-life situations by actively engaging the learner.

No significant difference was found on the final questionnaire score, which is consistent with a previous study [20] and may suggest that journal article reading can still lead to sufficient knowledge for continuing education but that Hygie is at least noninferior to traditional methods.

\section{Limitations and Strengths}

There were some limitations to our study.

Recruitment was limited to GPs who were resident supervisors. This population is representative of the French GP population with some particularities such as a higher proportion of women, an underrepresented 45 to 54 years age group, a majority group practice, and a lower weekly working time [34]. Another bias is that participants were volunteered for the study after reading the email solicitation that offered to try a "new continuing education material." Thus, it was possible that this population of GPs was especially interested in updating their medical knowledge; this is supported by the proportion of physicians declaring reading the Prescrire journal in our study (70\%), which is much higher than the proportion of French GPs 
subscribing to Prescrire (18.1\% of GPs subscribed to Prescrire in 2016) [35].

The GPs' positive response rate for participating in the study was $7.9 \%$ (269 included out of 3398 requested), which is comparable with the average response rate in this population [36] but prevented us from reaching the number of participants suggested by our power analysis. The real response rate cannot be definitively known because it is possible that some emails failed to reach potential GPs and were not read.

Contamination bias between groups is a potential limitation, but limited access to 1 of the 2 teaching materials through the login and individual working environment of French GPs has limited this possibility.

More than half $(60 \%)$ of the participants did not complete the study, which may have been a consequence of the "real life" conditions of our trial (unconstrained use) and the fact that the study took place during the summer holidays. The similar number of participants who did not complete the study in the 2 groups (58\% in the Hygie group and 62\% in the control group) suggests that the reasons for not participating are not related to the nature of the teaching material. Similarly, it can be assumed that the influence of reminders during the week of access to teaching materials, compared with routine use, was similar for both groups. However, the final sample size was smaller than the number calculated as required. A lack of power may explain that 1 of the 2 end points did not reach statistical significance.

Knowledge and satisfaction questionnaire have not been previously validated because they have been made to match the content of the teaching materials. The use of customized instruments is strongly recommended for the evaluation of serious games by Moreno-Ger [37], who argues that generic questionnaires are usually not useful for assessing games that can be very different in their objectives, target audiences, and needs. However, GPs experienced in medical pedagogy reviewed and improved these questionnaires, which was then pilot tested.

The scores obtained by the participants in the pretest knowledge questionnaire were surprisingly low. The lack of knowledge of clinical practice recommendations by French GPs is known in the literature [38]. In addition, the knowledge questionnaire presented several difficulties: free-text responses and needing to know recent evidence-based recommendations. The improvement in scores between pretest and posttest, although significant in both groups, may appear small. In addition to the difficulty of the questionnaire, which may have limited the progression of participants, this slight increase can be explained by the forgetting of knowledge.

The duration between the end of access to the teaching materials and the final test questionnaire was chosen at 3 to 5 weeks to evaluate long-term memorization, the most relevant type of memorization for the GP, and to limit the number of people lost to follow-up over a too long a period. We based our decision of follow-up period on a study conducted in 2008 evaluating the long-term memorization by residents of recommendations on type 2 diabetes learned via an internet tutorial [39]. Subjects were randomized into 6 groups that varied the time between the tutorial and the knowledge assessment: without delay and with delay of 1 day, 3 days, 8 days, 21 days, and 55 days. At 21 days, the interns had forgotten more than half of the knowledge learned compared with those assessed without any delay, suggesting that this duration allows long-term learning to be assessed.

The time spent on learning material could not be collected automatically in control group. These data would have provided an additional element of comparison between the 2 groups. However, as the groups were randomized, the effect of individual preferences regarding time allocation can be assumed to be balanced between groups. The self-reported time of participants was more than 2 times longer in the Hygie group; it is possible that this result indicates that Hygie is more time-consuming than reading. However, in the "real life" conditions of this trial, where each participant chose the time spent on the support, it seems that this result is rather in favor of Hygie's interest. That is, this educational support seems particularly engaging in this population of GPs, who are known to lack time and motivation for continuing education.

\section{Conclusions}

A very favorable reception was given by most GPs who used the Hygie game, particularly for its playful, interactive, and stimulating aspects, which supported the engaging learning experience.

In this study, many GPs spent much time on Hygie, commenting favorably on the clinical cases and the resulting learning experiences. A large proportion of participants expressed a desire to use it regularly for continuing education. In addition, Hygie serious game inspired many participants to subscribe to journals, which implies a synergy of this novel approach with the traditional article reading approach.

Our pragmatic study suggests that under usual conditions with e-learning teaching material, Hygie game can be an effective, pleasant, and engaging method for continuing education of GPs. It can be widely disseminated at low cost. Its modular content allows for future adaptation and improvement, and immersive qualities in a virtual reality where errors are not detrimental to patients render it an exciting next direction for adult learning among GPs and other physicians. In the future, we could evaluate the appropriation of this tool by GPs and their ability to improve it.

\section{Acknowledgments}

The authors would like to thank Prescrire journal, Minerva journal, French university departments, and resident supervisors for participating in this study; Prof Jean-Pierre Aubert, Prof Jean-François Bergmann, and Dr Josselin Le Bel for creating the knowledge questionnaire; and Stéphanie Sidorkiewicz, Alexandre Malmartel, and Pascal Bessonneau for making corrections in the manuscript. 


\section{Conflicts of Interest}

L-BJ is the owner of the Hygie (hygie-jeu.fr) website. No other COI declared.

\section{Multimedia Appendix 1}

CONSORT-EHEALTH checklist (V 1.6.1).

[PDF File (Adobe PDF File), 393 KB-Multimedia Appendix 1]

\section{References}

1. Kelly M, Murray TS. General practitioners' views on continuing medical education. Br J Gen Pract 1994 Oct;44(387):469-471 [FREE Full text] [Medline: 7748636]

2. Pitts J, Curtis A, While R, Holloway I. 'Practice professional development plans': general practitioners' perspectives on proposed changes in general practice education. Br J Gen Pract 1999 Dec;49(449):959-962 [FREE Full text] [Medline: 10824338]

3. ORS Pays de la Loire. General practitioners face the challenge of updating knowledge and practices and the issue of remuneration methods. Pays de la Loire: URML des Pays de la Loire; 2009.

4. Davis DA, Thomson MA, Oxman AD, Haynes RB. Evidence for the effectiveness of CME. A review of 50 randomized controlled trials. J Am Med Assoc 1992 Sep 2;268(9):1111-1117. [doi: 10.1001/jama.1992.03490090053014] [Medline: 1501333]

5. Grol R, Grimshaw J. From best evidence to best practice: effective implementation of change in patients' care. Lancet 2003 Oct 11;362(9391):1225-1230. [doi: 10.1016/S0140-6736(03)14546-1] [Medline: 14568747]

6. Mouaheb H, Fahli A, Moussetad M, Eljamali S. The serious game: what educational benefits? Procedia - Soc Behav Sci 2012;46:5502-5508. [doi: 10.1016/j.sbspro.2012.06.465]

7. Ricci KE, Salas E, Cannon-Bowers JA. Do computer-based games facilitate knowledge acquisition and retention? Mil Psychol 2009;8(4):295-307. [doi: 10.1207/s15327876mp0804 3]

8. Mayo MJ. Games for science and engineering education. Commun ACM 2007;50(7):30-35. [doi: 10.1145/1272516.1272536]

9. Larsen DP, Butler AC, Roediger HL. Repeated testing improves long-term retention relative to repeated study: a randomised controlled trial. Med Educ 2009 Dec;43(12):1174-1181. [doi: 10.1111/j.1365-2923.2009.03518.x] [Medline: 19930508 ]

10. Roediger HL, Butler AC. The critical role of retrieval practice in long-term retention. Trends Cogn Sci 2011 Jan;15(1):20-27. [doi: 10.1016/j.tics.2010.09.003] [Medline: 20951630]

11. Kerfoot BP, Baker H. An online spaced-education game for global continuing medical education: a randomized trial. Ann Surg 2012 Jul;256(1):33-38. [doi: 10.1097/SLA.0b013e31825b3912] [Medline: 22664558]

12. Asad M, Iqbal K, Sabir M. Effectiveness of problem based learning as a strategy to foster problem solving and critical reasoning skills among medical students. J Ayub Med Coll Abbottabad 2015;27(3):604-607. [Medline: 26721019]

13. Walljasper D. Games with goals. Nurse Educ 1982;7(1):15-18. [doi: 10.1097/00006223-198201000-00014] [Medline: $\underline{6915390]}$

14. Beylefeld AA, Struwig MC. A gaming approach to learning medical microbiology: students' experiences of flow. Med Teach 2007 Nov;29(9):933-940. [doi: 10.1080/01421590701601550] [Medline: 18158668]

15. Dankbaar M. Serious games and blended learning; effects on performance and motivation in medical education. Perspect Med Educ 2017 Mar;6(1):58-60 [FREE Full text] [doi: 10.1007/s40037-016-0320-2] [Medline: 27975195]

16. Allery LA. Educational games and structured experiences. Med Teach 2004 Sep;26(6):504-505. [doi: 10.1080/01421590412331285423] [Medline: 15763824]

17. Akl E, Sackett KM, Erdley WS, Mustafa RA, Fiander M, Gabriel C, et al. Educational games for health professionals. Cochrane Database Syst Rev 2013 Jan 31(1):CD006411. [doi: 10.1002/14651858.CD006411.pub3] [Medline: 23440807]

18. Ricciardi F, de Paolis LT. A comprehensive review of serious games in health professions. Int J Comput Games Technol 2014;2014:1-11. [doi: 10.1155/2014/787968]

19. Diehl LA, Souza RM, Alves JB, Gordan PA, Esteves RZ, Jorge ML, et al. InsuOnline, a serious game to teach insulin therapy to primary care physicians: design of the game and a randomized controlled trial for educational validation. JMIR Res Protoc 2013 Jan 21;2(1):e5 [FREE Full text] [doi: 10.2196/resprot.2431] [Medline: 23612462]

20. Diehl LA, Souza RM, Gordan PA, Esteves RZ, Coelho IC. InsuOnline, an electronic game for medical education on insulin therapy: a randomized controlled trial with primary care physicians. J Med Internet Res 2017 Mar 9;19(3):e72 [FREE Full text] [doi: 10.2196/jmir.6944] [Medline: 28279950]

21. Signoret J. SFMG Wealth Advisors. 2012. Evolution du contenu de la consultation de Médecine Générale en termes de maladies chroniques, aigues et de prises en charge non pathologiques entre 1993 et 2010 URL: http://www.sfmg.org/data/ generateur/generateur fiche/728/fichier these juliensignoretccb5a.pdf [accessed 2017-02-02]

22. La rédaction Prescrire. Hypertension artérielle essentielle chez l'adulte : premiers traitements. Rev Prescrire 2016 Jan:1-5.

23. La rédaction Prescrire. Traitement de l'hypertension arterielle essentielle : Un diuretique thiazidique en premier choix, le plus souvent. Rev Prescrire 2014 Apr:275.

24. Baeten R, Medica D. Preventive health checks: a health benefit? Minerva 2014;13(2):15-16 [FREE Full text] 
25. La rédaction Prescrire. Coloscopies de dépistage: ne pas négliger les risques. Rev Prescrire 2015 Jun:453.

26. La rédaction Prescrire. Papillomavirus vaccines and Guillain-Barré syndromes: managing uncertainties. Rev Prescrire 2016;36(392):427-432 [FREE Full text]

27. La rédaction Prescrire. Patients ayant une hyperlipidémie. Rev Prescrire 2016;Guide Interactions médicamenteuses:159-167.

28. Niven D, Gaudet J, Laupland K. Brief analysis: are peripheral thermometers accurate enough to measure body temperature? Minerva 2016 May;Analyse brève:1-2 [FREE Full text]

29. Van den Bruel A, Haj-Hassan T, Thompson M. Diagnostic ambulatoire d?infections sévères chez les enfants. Minerva 2010 Dec;9(11):128-129.

30. La rédaction Prescrire. Rhume: Premiers Choix Prescrire, actualisation. Rev Prescrire 2015 Jul:1-4.

31. Jaunay L-B. Hygie game URL: http://hygie-jeu.fr/etude/ [accessed 2018-10-22] [WebCite Cache ID 73MXeHztv]

32. R: The R Project for Statistical Computing. URL: https://www.r-project.org/ [accessed 2018-08-20]

33. Schulz KF, Altman DG, Moher D, CONSORT Group. CONSORT 2010 statement: updated guidelines for reporting parallel group randomised trials. Br Med J 2010 Mar 23;340:c332 [FREE Full text] [doi: 10.1136/bmj.c332] [Medline: 20332509]

34. Bouton C, Leroy O, Huez J, Bellanger W, Ramond-Roquin A. Representativeness of General Practitioners university teachers. Public Health 2015;27(1):59-67. [doi: 10.3917/spub.151.0059]

35. La rédaction Prescrire. Les finances de l'Association Mieux Prescrire. Bilan de l'exercice 2015-2016. Rev Prescrire 2017:164-165.

36. Chevallier R. Banque de données en santé publique. 2017. Evaluation of an internal site for the management of type 2 diabetic patients, for use by general practitioners URL: http://bdsp-ehesp.inist.fr/vibad/index. php?action=getRecordDetail\&idt=525817 [accessed 2019-07-26]

37. Moreno-Ger P, Torrente J, Hsieh YG, Lester WT. Usability testing for serious games: making informed design decisions with user data. Adv Hum-Comput Interact 2012;2012:1-13. [doi: 10.1155/2012/369637]

38. Morawski-Bachimont J, Cogneau J, Letourmy A. Why general practitioners do not respect recommendations for good clinical practices? The case of non insulin dependent diabetes mellitus. Sci Soc Santé 2006;24(2):75-103. [doi: 10.3406/sosan.2006.1681]

39. Bell DS, Harless CE, Higa JK, Bjork EL, Bjork RA, Bazargan M, et al. Knowledge retention after an online tutorial: a randomized educational experiment among resident physicians. J Gen Intern Med 2008 Aug;23(8):1164-1171 [FREE Full text] [doi: 10.1007/s11606-008-0604-2] [Medline: 18446414]

\title{
Abbreviations \\ DQ-5: Dynamic Questionnaire-5 \\ e-learning: electronic learning \\ GP: general practitioner \\ PHP: Hypertext Preprocessor \\ SQ-20: Static Questionnaire-20
}

\author{
Edited by G Eysenbach; submitted 01.11.18; peer-reviewed by K Glover, J Kaewkungwal; comments to author 05.04.19; revised \\ version received 17.06.19; accepted 19.07.19; published 20.11.19 \\ Please cite as: \\ Jaunay LB, Zerr P, Peguin L, Renouard L, Ivanoff AS, Picard H, Griffith J, Chassany O, Duracinsky M \\ Development and Evaluation of a New Serious Game for Continuing Medical Education of General Practitioners (Hygie): \\ Double-Blinded Randomized Controlled Trial \\ J Med Internet Res 2019;21(11):e12669 \\ URL: http://www.jmir.org/2019/11/e12669/ \\ doi: $\underline{10.2196 / 12669}$ \\ PMID: 31746775
}

CLouis-Baptiste Jaunay, Philippe Zerr, Lino Peguin, Léandre Renouard, Anne-Sophie Ivanoff, Hervé Picard, James Griffith, Olivier Chassany, Martin Duracinsky. Originally published in the Journal of Medical Internet Research (http://www.jmir.org), 20.11.2019. This is an open-access article distributed under the terms of the Creative Commons Attribution License (https://creativecommons.org/licenses/by/4.0/), which permits unrestricted use, distribution, and reproduction in any medium, provided the original work, first published in the Journal of Medical Internet Research, is properly cited. The complete bibliographic information, a link to the original publication on http://www.jmir.org/, as well as this copyright and license information must be included. 